\title{
Self-stigma and cognitive fusion in parents of children with autism spectrum disorder. The moderating role of self- compassion
}

\author{
Anna Pyszkowska ${ }^{\text {Corresp., }}{ }^{1}$, Krzysztof Rożnawski ${ }^{1}$, Zuzanna Farny ${ }^{1}$ \\ ${ }^{1}$ University of Silesia, Katowice, Poland \\ Corresponding Author: Anna Pyszkowska \\ Email address: anna.pyszkowska@us.edu.pl
}

Background. Research shows that people with autism spectrum disorder and their families often experience social stigma. The internalization of social stigma can lead to the occurrence of self-stigma, understood as an internalized cognitive-affective self-directed and rigid process that results in individuals agreeing with stigmatizing opinions and applying them to themselves. Experiencing self-stigma can lead to a cognitive fusion with negative thoughts - especially those about oneself. Previous studies show that selfcompassion reduces feelings of suffering, shame and self-stigma in a group of parents of children with autism spectrum disorder.The aim of this study was to test the relationship between self-stigma and cognitive fusion among parents of children with ASD. The moderating role of self-compassion as a protective factor was also verified. Methods. The following questionnaires were used: Perceived Public Stigma Scale, Perceived Courtesy Stigma Scale, Self-Compassion Scale - Short Form, Cognitive Fusion Questionnaire, and Depression, Anxiety and Stress Scale. Thestudy included 233 Polish parents of children with autism spectrum disorder (including 218 women). Results. The results showed a positive correlation between fusion and bothaffiliate $(r=.31, p<.001)$ and public stigma $(r$ $=.33, p<.001)$. Fusion and self-compassion were significant predictors of affiliate stigma. Self-compassionmoderated therelationship between fusion and depression ( $\beta=-.11, p<$ $.05)$ and the relationship between fusion and stress $(\beta=-.11, p<.05)$. Cognitive fusion with negative beliefs about oneself can contribute to self-stigma. Defusion-oriented actions are an opportunity to distance oneself from emerging thoughts and eliminate their negative consequences. Self-compassion manifests itself in a compassionate and accepting attitude towards oneself and improves the individual's well-being. Actions taken to strengthen the indicated factors could contribute to a better quality of life of parents of children with ASD. 
1 Self-stigma and cognitive fusion in parents of children with autism spectrum disorder. The

2 moderating role of self-compassion

3

4 Anna Pyszkowska ${ }^{1}$, Krzysztof Rożnawski ${ }^{1}$, Zuzanna Farny ${ }^{1}$

$5 \quad{ }^{1}$ Institute of Psychology, University of Silesia in Katowice

7 Corresponding Author:

8 Anna Pyszkowska

9 Grażyńskiego 53, 40-126, Katowice, Poland

10 anna.pyszkowska@us.edu.pl

Abstract

Background. Research shows that people with autism spectrum disorder and their families often experience social stigma. The internalization of social stigma can lead to the occurrence of selfstigma, understood as an internalized cognitive-affective self-directed and rigid process that results in individuals agreeing with stigmatizing opinions and applying them to themselves. Experiencing self-stigma can lead to a cognitive fusion with negative thoughts - especially those about oneself. Previous studies show that self-compassion reduces feelings of suffering, shame and self-stigma in a group of parents of children with autism spectrum disorder. The aim of this study was to test the relationship between self-stigma and cognitive fusion among parents of children with ASD. The moderating role of self-compassion as a protective factor was also 22 verified.

Methods. The following questionnaires were used: Perceived Public Stigma Scale, Perceived Courtesy Stigma Scale, Self-Compassion Scale - Short Form, Cognitive Fusion Questionnaire, and Depression, Anxiety and Stress Scale. The study included 233 Polish parents of children with autism spectrum disorder (including 218 women).

27 Results. The results showed a positive correlation between fusion and both affiliate $(\mathrm{r}=.31, \mathrm{p}$ $28<.001)$ and public stigma $(\mathrm{r}=.33, \mathrm{p}<.001)$. Fusion and self-compassion were significant 
29 predictors of affiliate stigma. Self-compassion moderated the relationship between fusion and 30 depression $(\beta=-.11, \mathrm{p}<.05)$ and the relationship between fusion and stress $(\beta=-.11, \mathrm{p}$ $31<.05)$. Cognitive fusion with negative beliefs about oneself can contribute to self32 stigma. Defusion-oriented actions are an opportunity to distance oneself from emerging thoughts 33 and eliminate their negative consequences. Self-compassion manifests itself in a compassionate 34 and accepting attitude towards oneself and improves the individual's well-being. Actions taken to 35 strengthen the indicated factors could contribute to a better quality of life of parents of children 36 with ASD.

37 


\section{Introduction}

The third wave of cognitive-behavioral therapies (CBT) is characterized by themes such as metacognition, mindfulness, dialectics, cognitive fusion, acceptance of emotions (Kahl, Winter, Schweiger, 2012), or self-compassion (Hayes, 2004). In contrast to classic cognitivebehavioral therapy's focus on cognitive restructuring and emotion changing, the third wave concentrates primary on the psychological and behavioral processes associated with mental health and well-being, and their contexts (Hofmann \& Hayes, 2019). Acceptance and Commitment Therapy (ACT) represents one of the third wave's approaches and its core goal is to develop psychological flexibility via acceptance, mindfulness and values-focused behavioral strategies (Hayes et al., 1999). Research shows that ACT is effective in patients with anxiety disorders or depression (Forman, et al. 2007), and its role is also significant when working with stigmatized groups of minorities (Skinta, et al. 2014) such as parents of children with autism spectrum disorder (ASD, cf. Lunksy, et al., 2018).

Parents of children with ASD experience elevated levels of stress a lot of times due to different challenges they face during caregiving for their children (Hayes \& Watson, 2013; Chan \& Lam, 2017). Studies have compared the amount of stress parents of children with ASD experience to other groups, such as parents of children with typical development or those diagnosed with other disorders (Hayes \& Watson, 2013): out of all those groups it has been proven that the levels of stress in families of children with ASD are the highest (Hayes \& Watson, 2013). In addition, it can be observed that the risk of depression and anxiety within this group seems higher too (Hamlyn-Wright, et al. 2007). Research shows that ACT is an effective approach in reducing depressive symptoms and enhancing well-being and psychological flexibility in parents of children with ASD (Corti et al., 2018; Blackledge \& Hayes, 2006). Harris (2012) suggests that psychological flexibility, including defusion, acceptance and selfcompassion may be considered as a protective factor while experiencing a gap between expectations and reality that cannot be changed.

One of the challenges parents of children with ASD face is the societal stigma directed towards their children and themselves (Kinnear, et al. 2016). Due to certain features of ASD poor social skills, inappropriate affective expressions, self-destructive acts, and language impairments - people with a diagnosis of ASD are likely to experience stigmatizing reactions from the general public (Butler \& Gillis, 2011), such as insensitive comments, hostile stares, or 
69

even physical aggression (Lovell \& Wetherell, 2019). Previous research highlights that stigmatized individuals may develop self-stigma, defined as an internalized cognitive-affective self-directed and rigid process that results in the individuals agreeing with stigmatizing opinions and applying them to themselves (Smith-Palmer et al., 2020). Self-stigma may comprise public stigma and affiliate stigma. Public stigma refers to stereotypical beliefs, prejudicial attitudes and discriminatory behaviors endorsed by a sizable group in society toward a discredited subgroup (Corrigan \& Watson 2002). Affiliate stigma refers to the extent of self-stigmatization among associates of the targeted minorities (Mak \& Cheung, 2008), including parents of individuals with ASD (Chan \& Lam, 2017).

Research shows that parents of children with ASD may experience being blamed by others as guilty for causing their children's disability (Wong, Mak \& Liao, 2016), or seen as responsible for their children's behavior (Myers et al., 2009). Therefore, they might be stigmatized alongside their children, which may result in affiliate stigma (Chan \& Lam, 2017). This experience often leaves parents feeling humiliated, isolated, and judged (Broady, Stoyles \& Morse, 2017), hence they may internalize the content of stigmatizing words and thoughts, and therefore social stigma can be transformed into self-stigma; when this happens, individuals seem to accept negative social judgments and incorporate them into their own value system (Chan \& Lam, 2018). In consequence, the development of negative self-thoughts intensifies, hence one’s self-esteem and self-efficacy may decrease, causing individuals to experience higher levels of stress and diminishing their well-being (Corrigan, Rafacz \& Rusch, 2011; Lovell \& Wetherell, 2019). Based on these factors, self-stigma may make caregiving responsibilities more difficult for parents and play a negative role in their relationship with the child (Chan \& Lam, 2017). Research suggests that acceptance and commitment therapy-based interventions may improve parents’ well-being (Corti et al., 2018; Blackledge \& Hayes, 2006), while internal resources such as defusion and self-compassion may act as potential protective factors against distress (Marsh et al., 2018; Maisel et al., 2019) and self-stigma (Yadavaia \& Hayes, 2021).

Fusion and defusion are processes central to the psychological flexibility model that forms the basis of Acceptance and Commitment Therapy (Hayes et al., 1999). Cognitive fusion refers to the tendency for behavior to be overly-regulated and influenced by cognition. The behavior and the experience of a "fused" person is dominated by thoughts, and as a consequence he/she becomes less sensitive to direct consequences in their environment (Gillanders et al., 2014). A person who experiences a rigidly fused relationship with their inner content will treat their 
101 thoughts with seriousness, as if the thoughts were a true narrative on their reality. This narrows

102 down the ways in which the individual can think freely and take effective action in their life. The 103 opposite - cognitive defusion - is an ability to see their experience as mere thoughts, not as a 104 commanding reflection of a one true (and often very judgmental) reality.

105 The cognitive content of self-stigma usually consists of stereotypical beliefs aimed toward 106 a discredited group (Corrigan \& Watson 2002). A person "fused” with stereotypical beliefs is 107 going to act on them as though they were literally true. For example, a parent of a child with ASD 108 "fused" with the thought "most people from my community would rather not be friends with 109 families that have a member who has an ASD” most likely would abstain from participating in social events in the neighborhood and be hesitant about taking any action that could strengthen their relationship with a member of the community. Such a person is probably going to be insecure and tentative among others that know him or her to be a parent of a child with an ASD. Hence, experiencing stigma may heighten the probability of cognitive fusion, particularly for negative self-relevant thoughts. This may happen because experiencing a stigma increases the possibility of developing a distressing self-story. Research on internalized mental illness stigma showed that experiencing discrimination due to one's mental illness is associated with increased anticipated discrimination in the future, increased social stigma from others, and greater internalized stigma (Quinn et al., 2015).

As proposed by Neff (2003b), self-compassion shares three properties: self-kindness, common humanity and mindfulness. Respectively, they entail treating oneself in a friendly manner, seeing one's own difficulties as a part of the human condition, and being able to live one’s own “stories” (self-narrative) gently, without overexaggerating. Kirby, Tellegen and Steindl (2017) conducted a meta-analysis on 21 randomized controlled trial studies examining the effects of compassion-based interventions. As a result, they found that self-compassion reduces human suffering, and specifically lowers levels of depression, anxiety and distress. There are also studies that underline self-compassion's role as a mediator between resilience in the face of adversity and mental well-being (Trompetter et al., 2017; Kotera et al., 2020). Self-compassion is related to higher life-satisfaction, lower levels of worry (Mowlaie et al., 2017) and posttraumatic growth (Basharpoor et al., 2020), and it is negatively correlated with self-criticism (Neff \& McGheea; 2010). Luoma and Platt (2015) indicate that ACT processes are to some extent practically self-compassionate. They further imply that shame is the core emotion in the experience of stigma (Luoma et al., 2012). Shame has a socially distancing and isolating effect 
133 (Dickerson et al., 2004; Dorahy 2010), as a person “fused” with shame-related cognitions will narrow down their behavior to such that will reflect the "fused" narrative and provide relief from unwanted but self-generated feelings. Compassion has a tendency to coexist with a different set of emotions such as sympathetic joy, warmth, interest and pride (Goetz et al., 2010) and endorse different behaviors. To be self-compassionate means to relate kindly to one's own experiences and to be caring towards oneself (Luoma \& Platt, 2015). Luoma and Platt (2015) argue that selfcompassion is an implicit ACT process that has an impact on the effectiveness of ACT interventions for shame and stigma. ACT proved effective in reducing shame related to substance addiction (Luoma et al., 2008), self-stigma related to obesity (Lillis et al., 2009), sexuality (Yadavaia \& Hayes, 2012), psychological disorders (Masuda et al., 2007) and HIV when combined with Compassion Focused Therapy (Skinta et al., 2014). Vowles et al. (2014) found that self-compassion was the strongest mediator in justifying the positive effect of ACT among patients with chronic pain.

While having certain emotions is not typically associated with either the presence or the absence of fusion, chronic shame, anxiety, and depression can be seen as a reflection of an underlying narrow, rigid and constricting "fused” relationship with own inner content (Hayes et al., 2011; Valvano et al., 2016). Seen this way, a self-compassionate perspective on oneself and others should undermine this schematic, chronic pattern of thinking and feeling. Also, it is worth noting that self-compassion was significantly and negatively correlated with cognitive fusion in patients with chronic pain (cognitive fusion mediated the relationship between the chronic pain and depression symptoms, and self-compassion at all levels moderated that correlation; (Carvalho et al., 2018), in individuals with childhood abuse experience (Basharpoor et al., 2020) and in cancer patients (Gillanders et al., 2015). Self-compassion was found to be the moderator between affiliate stigma and distress in parents of children with autism spectrum disorder (Wong et al., 2016). The predictive effect of self-stigma on psychological variables such as depression, somatic symptoms, health status or quality of life was reduced by self-compassion by approximately onethird in overweight and obesity (Hilbert et al., 2015).

The current study design was similar to the one presented by Chan and Lam (2017). The aim of the current study was to determine relationships between self-stigma and cognitive fusion and their effect on affective symptoms in parents of children with ASD. The study focused on whether self-stigma (affiliate stigma and public stigma) and cognitive fusion predicted depression, anxiety and stress in parents of children with ASD. Also, it was decided to add self- 
165 compassion to the model as it was reported to decrease the effect of self-stigma-related attitudes

166 in minority groups (Wong et al., 2016) and to be highly associated with mindfulness (Neff, 2003)

167 also reported as a protective factor against self-stigma (Chan \& Lam, 2018). It was hypothesized 168 that affiliate stigma and public stigma would be linked with higher levels of depression, anxiety 169 and stress, and increase with higher levels of cognitive fusion. Moreover, it was hypothesized that 170 parents with a more self-compassionate attitude would present weaker links between self-stigma, 171 fusion and affective symptoms.

\section{Materials and Methods}

This study was approved by the Ethics Committee of the University of Silesia in Katowice (approval no.: KEUS.92/02.2021). All participants provided written informed consent prior to enrolment in the study.

Nonprobability sampling was used. The inclusion criterion was being a parent of a child with a diagnosis of autism spectrum disorder (F84.0). Participants were recruited in schools, kindergartens and ASD-dedicated foundations in Poland via Internet. A total of 233 parents of children with ASD participated in the present study using an on-line survey. The majority of parents were female (93\%), most of them had higher education (57\%) and were married (71\%). Most participants worked part-time (46\%) or full-time (43\%) jobs. The majority of children were male (84\%) and had no intellectual disability (52\%). Sociodemographic data is presented in Table 1. Despite the noticeable disproportion in terms of gender in favor of females, it was decided to use data from both the mothers and the fathers. This was due to the fact that a significant part of the research conducted so far has also faced the problem related to the small amount of data regarding experiences of fathers of children with ASD, so it was decided to take into account at least a small part of it, with the proviso that the results obtained could be generalized to reflect the experiences of all men. 
195 Public Stigma Scale (Chan \& Lam, 2017) and Perceived Courtesy Stigma Scale (Chan \& Lam, 196 2017) using the back translation method. No pilot testing was conducted on the normative sample 197 due to the specific content of both questionnaires aimed at parents of children with autism 198 spectrum disorder (Chan \& Lam, 2017). The translators were granted approval by the authors of 199 the original questionnaires. Participants who decided to be involved in the study filled by 200 themselves the following tools:

201 Public stigma. Perceived public stigma was measured using the Perceived Public Stigma Scale 202 (PPSS; Chan \& Lam, 2017, Polish translation for the purpose of this study by Pyszkowska \& 203 Rożnawski, unpublished). The Scale contained eight items adapted from Green’s (2001) study. A 204 sample item was "Most people feel that having an ASD is a sign of personal failure". Participants 205 rated each item on a 6-point Likert scale ranging from 0 (strongly disagree) to 5 (strongly agree). 206 In the present study, Cronbach’s alpha was $\alpha=.88$.

207 Affiliate stigma. Affiliate stigma was measured using the Perceived Courtesy Stigma Scale 208 (PCSS; Chan \& Lam, 2017, Polish translation for the purpose of this study by Pyszkowska \& 209 Rożnawski, unpublished), which contained seven items adapted from the Devaluation of 210 Consumer Families Scale by Struening et al., 2001. A sample item was "Most people do blame 211 parents for the ASD of their children”. Participants rated each item on a 4-point Likert scale 212 ranging from 0 (strongly disagree) to 3 (strongly agree). In the present study, Cronbach's alpha 213 was $\alpha=.86$.

214 Self-compassion. Self-compassion was measured using the Self-Compassion Scale - Short Form 215 (SCS-SF; Raes, et al., 2011; Polish translation by Kocur, unpublished), which contained twelve 216 items adapted from the Self-Compassion Scale (SCS; Neff, 2003a). A sample item was "When 217 I'm going through a very hard time, I give myself the caring and tenderness I need”. Participants 218 rated each item on a five-point Likert scale ranging from 1 (almost never) to 5 (almost always). 219 In the present study, Cronbach’s alpha was $\alpha=.83$.

220 Cognitive fusion. Cognitive fusion was measured using the Cognitive Fusion Questionnaire 221 (Gillanders et al., 2014; Polish translation: Baran et al., 2019) which contained seven items (e.g. 222 “I struggle with my thoughts”). Participants rated each item on a seven-point Likert scale ranging from 1 (never true) to 7 (always true). In the present study, Cronbach’s alpha was $\alpha=.93$.

224 Depression, anxiety and stress. Depression, anxiety and stress symptoms were measured through 225 the Depression, Anxiety and Stress Scale (DASS-21, Lovibond \& Lovibond, 1995, Polish 
226 translation by Makara-Studzińska et al., in preparation) which contained twenty-one items. A 227 sample item was “I felt life was meaningless”. Participants rated each item on a four-point Likert 228 scale ranging from 0 (rarely or never) to 3 (most of the time). In the present study, Cronbach's alpha was as following: $\alpha$ for depression $=.93, \alpha$ for anxiety $=.94, \alpha$ for stress $=.92$.

\section{Results}

All calculations were performed with the use of Jamovi 1.6.23.

Demographic variables were analyzed through descriptive statistics. Bivariate correlation analyses were performed to examine relationships between independent variables (affiliate stigma, public stigma, cognitive fusion), the moderator variable (self-compassion), and dependent variables (depression, anxiety, stress). First, a hierarchical multiple regression model was used in order to determine predictors (affiliate stigma, public stigma, fusion) of depression, anxiety and stress while controlling for parent's professional status, parent's level of education, and the child's level of intellectual disability. Then, six hierarchical multiple regression models were conducted including an interaction term between two predictors: self-stigma and fusion, and a moderator (self-compassion). The independent and moderator variables were standardized before the interaction term was computed to reduce multicollinearity. In step 1, standardized covariates were entered (parent's professional status, parent's level of education and child's level of intellectual impairment). In step 2, standardized independent and moderator variables were added, and finally, in step 3, two separate interactions between predictors (affiliate or public stigma and fusion) and moderator (self-compassion) were included. For statistically significant interactions, simple slope tests were conducted to examine whether the effects of the independent variables on the dependent variables were significant for high (+1 SD), medium (1 SD) and low (-1 SD) levels of the moderator.

ANOVA test showed no significant differences between parents of children with various levels of ASD-related intellectual disability except for affiliate stigma $(\mathrm{F}=2.60, \mathrm{p}=.05)$. Bonferroni-corrected contrasts revealed differences between parents of children with moderate and severe intellectual disability $(\mathrm{t}=-2.55, \mathrm{p}=.05)$. Therefore, it was decided to conduct all analyses without grouping. Descriptive statistics and Pearson's r correlations between variables studied are summarized in Table 2. 
257 [Table 2]

258

Above-average rates of depression $(\mathrm{M}=16.65)$, anxiety $(\mathrm{M}=18.96)$ and stress $(\mathrm{M}=$

14.02) were recognized. Both affiliate $(r=.31, \mathrm{p}<.001)$ and public stigma $(\mathrm{r}=.33, \mathrm{p}<.001)$

showed significant positive associations with fusion, as well as with depression $r_{\text {affiliate }}=.33, p$ $\left.<.001), \mathrm{r}_{\text {public }}=.36, \mathrm{p}<.001\right)$, anxiety $\left(\mathrm{r}_{\text {affiliate }}=.35, \mathrm{p}<.001, \mathrm{r}_{\text {public }}=.38, \mathrm{p}<.001\right)$ and stress

$\left(\mathrm{r}_{\text {affiliate }}=.35, \mathrm{p}<.001 ; \mathrm{r}_{\text {public }}=.37, \mathrm{p}<.001\right)$. Self-compassion showed negative correlations with both affiliate $(r=-.24, \mathrm{p}<.001)$ and public stigma $(\mathrm{r}=-.32, \mathrm{p}<.001)$. Fusion was positively correlated with all negative symptoms ( $\mathrm{r}$ range $=.64-.66, \mathrm{p}<.001$ ) while self-compassion showed negative associations ( $\mathrm{r}$ range $=.-.52--.59, \mathrm{p}<.001$ ).

Tables 3 and 4 present hierarchical regression models.

[Table 3] $2 \%(F=2.837)$ of depression, with significance of the parental education level $(\beta=.20, p<.01)$. An addition of main effects explained a further $48 \%(F=39.077)$ of variance (affiliate stigma $\beta=$ $.16, \mathrm{p}<.01$; self-compassion $\beta=-.17, \mathrm{p}<.01$; fusion $\beta=.50, \mathrm{p}<.001$ ). Interaction effects explained an additional $1 \%$, ( $F=30.530)$ with the significance of the moderating effect on fusion $(\beta=-.10, \mathrm{p}<.05)$. Simple slope tests showed (see Fig. 1$)$ that a high level of self-compassion was associated with a smaller $(\beta=4.85, \mathrm{SE}=.59, \mathrm{p}<.001)$ effect of fusion on depressive symptoms when compared to low rates of self-compassion $(\beta=6.90, \mathrm{SE}=.53, \mathrm{p}<.001)$. In the case of anxiety, background factors explained $4 \%(F=3.044)$ with the parental education level being the only significant factor $(\beta=.19, \mathrm{p}<.05)$, while main effects constituted a further $47 \%$ $(\mathrm{F}=42.109$; affiliate stigma $\beta=.18, \mathrm{p}<.001$; self-compassion $\beta=-.27, \mathrm{p}<.001$; fusion $\beta=.41$, $\mathrm{p}<.001)$. An addition of interaction effects did not enhance the variance $(\mathrm{F}=32.112)$. Background factors predicted $1 \%$ of stress $(F=2.117$; parental education level $\beta=.16, p<.05)$, an addition of main effects constituted another $46 \%(F=35.848$; affiliate stigma $\beta=.18, p$ $<.001$; self-compassion $\beta=-.14, \mathrm{p}<.05$; fusion $\beta=.50$, $\mathrm{p}<.001$ ). Interaction effects explained 
286 an additional $2 \%$, ( $F=28.469)$ with the significance of the moderating effect on affiliate stigma $287(\beta=-.10, \mathrm{p}<.05)$. Simple slope tests showed (see Fig. 2) that a high level of self-compassion 288 was associated with a lower effect of affiliate stigma on stress $(\beta=2.11$, SE $=.74, p<.01)$ when compared to low rates of self-compassion $(\beta=6.90, \mathrm{SE}=.81, \mathrm{p}<.001)$.

[Figure 2]

[Table 4]

The hierarchical regression model revealed that in step 1, background factors predicted $2 \%$ of depression $(F=2.837)$, with significance of the parental education level $(\beta=.20, p<.01)$. An addition of main effects explained a further $47 \%$ of variance ( $F=37.995$; public stigma $\beta$ $=.13, \mathrm{p}<.01$; self-compassion $\beta=-.16, \mathrm{p}<.01$; fusion $\beta=.54, \mathrm{p}<.001$ ). Interaction effects explained an additional $1 \%$, $(F=29.752)$ with the significance of the moderating effect on fusion $(\beta=-.11, p<.05)$. Simple slope tests showed (see Fig. 3 ) that high level of self-compassion was associated with a smaller $(\beta=4.85, \mathrm{SE}=.59, \mathrm{p}<.001)$ effect of fusion on depressive symptoms when compared to low rates of self-compassion $(\beta=6.90, \mathrm{SE}=.81, \mathrm{p}<.001)$. In the case of anxiety, background factors explained 4\% ( $\mathrm{F}=3.044)$ with the parental education level being the only significant factor $(\beta=.19, \mathrm{p}<.05)$, while main effects constituted a further $47 \%(\mathrm{~F}=$ 40.594; public stigma $\beta=.15, \mathrm{p}<.01$; self-compassion $\beta=-.26, \mathrm{p}<.001$; fusion $\beta=.43$, $\mathrm{p}$ $<.001)$. An addition of interaction effects did not enhance the variance $(F=30.873)$. Background factors predicted $1 \%$ of stress ( $F=2.117$; parental education level $\beta=.16, p<.05)$, an addition of main effects constituted another $45 \%(\mathrm{~F}=34.605$; public stigma $\beta=.15, \mathrm{p}<.01$; selfcompassion $\beta=-.13, \mathrm{p}<.05$; fusion $\beta=.51, \mathrm{p}<.001)$. Interaction effects explained an additional $2 \%$, $(\mathrm{F}=27.42)$ with the significance of the moderating effect on fusion $(\beta=-.11, \mathrm{p}<.05)$. Simple slope tests showed (see Fig. 4) that a high level of self-compassion was associated with a lower effect of fusion on stress $(\beta=2.11$, $\mathrm{SE}=.74, \mathrm{p}<.01)$ when compared to low rates of selfcompassion $(\beta=6.90, \mathrm{SE}=.81, \mathrm{p}<.001)$. 
316 [Figure 3]

317 [Figure 4]

318

319 Discussion

The aim of this study was to verify associations between self-stigma, cognitive fusion and self-compassion in parents of children with autism spectrum disorder. It was confirmed that both affiliate $(\mathrm{r}=.31, \mathrm{p}<.001)$ and public stigma $(\mathrm{r}=.33, \mathrm{p}<.001)$ were moderately positively associated with cognitive fusion. As the roots of self-stigma are defined as rigid and conceptualized assumptions about oneself derived from opinions and beliefs regarding the object of stigma and the social image of the stigmatized person (Smith-Palmer et al., 2020), one might argue that self-stigma would be interpreted as a fusion with these assumptions, e.g. "since I am a bearer of a stigma, hence I am inherently defined by it”. As cognitive fusion is strongly associated with rigidity and narrow perspective (Hayes et al., 1999), it could be hypothesized that it would maintain or increase one's self-stigma narrative about oneself. On the contrary, defusion would act as a potential protective factor aimed at widening one's perspective and decrease the impact of self-stigma assumptions on the individual's mental health and well-being. On the other hand, the study showed an apparent negative link between self-compassion and fusion $(r=-.64$, $\mathrm{p}$ $<.001)$ and moderate correlations with affiliate $(\mathrm{r}=-.24, \mathrm{p}<.001)$ and public stigma $(\mathrm{r}=-.32, \mathrm{p}$ $<$.001). It could be considered to be in line with previous research regarding compassionate attitude towards oneself as flexible, non-judgmental (Neff \& Tirch, 2013) and negatively associated with fusion (Carvalho et al., 2018; Basharpoor et al., 2020) on the one hand, and negatively related to self-stigma (Wong et al., 2016) on the other hand.

Both models tested revealed that self-stigma (public and affiliate), self-compassion and fusion acted as significant predictors of depression, anxiety and stress among parents of children with autism spectrum disorder. Background factors and main effects accounted for 50\% of depression ( $F=39.077), 51 \%$ of anxiety $(F=42.109)$, and $47 \%$ of stress $(F=35.848)$ when affiliate stigma was used as a predictor, and $49 \%$ of depression $(F=37.995), 51 \%$ of anxiety $(F=$ 40.594), and $46 \%$ of stress $(F=34.605)$ when public stigma was used as a predictor. These results may suggest that it is not only public or affiliate stigma that affects psychological suffering in parents of children with ASD, but mostly their psychological resources, as fusion and self-compassion accounted for the highest rates of the estimates. As Hayes and Hofmann (2017) 
347 suggest, psychological resources such as flexibility are somewhat independent from 348 environmental factors, hence it is the function, not content, of thoughts or attitudes that is of 349 highest importance for one's relation to reality and experiences such as social comments or 350 stigmatization. Additionally, the parent's level of education was also a significant predictor, 351 which is in line with previous research (Chan and Lam, 2017), although this variable presented 352 far smaller estimates when compared to psychological functions.

353 Self-compassion acted as a significant moderator between affiliate stigma and depression 354 as well as fusion and depression or stress. In all cases, higher levels of self-compassion were 355 associated with smaller effects of fusion on psychological suffering (depressive or stress symptoms) or affiliate stigma on stress. Of note, self-compassion did not moderate relationships between self-stigma and anxiety perceived by participants of this study. It can be hypothesized that anxiety accompanies families of people with autism spectrum disorder in various contexts, irrelevant of the stigmatizing opinions of others or the parents themselves (e.g. fear of poor social support; dependence; finances, cf. Myers et al., 2009). The obtained results are in line with the reports by Wong et al. (2016) , as well as with the research by Chan and Lam (2017) using mindfulness as a moderator between self-stigma and depression and anxiety symptoms. It could be hypothesized that a compassionate attitude towards oneself may foster awareness of inner experience without suppression and over-identification (Neff, 2003a): thus, the stigmatized person can take a more level-headed view of the current situation and accept all aspects of their identity as they are. As a result, self-stigmatizing thoughts may no longer be the cause of psychological suffering, e.g. depressive or anxiety symptoms - although the aim of developing self-compassion or defusion is not to erase negative thoughts (Hayes et al., 1999), the decreasing of psychopathology can be considered as a side effect of their development (Chin \& Hayes, 2017).

Research shows that individuals with high self-compassion are capable of distinguishing between their sensory experience and mental experience of stigmatization, hence they would probably internalize the stigma (Wong et al., 2018), as well as may less likely suppress undesired thoughts and feelings (Neff, 2003a), acting more cognitively flexible (Martin et al., 2011). Both suppressing one's thoughts and feelings (experiential avoidance) and lack of cognitive flexibility are elements of cognitive fusion. Thus, it can be hypothesized that self-compassion may influence cognition in a way that protects the individual from cognitive fusion. 
380 Affiliate stigma was higher in parents of children with moderate or severe intellectual disability, 381 which can lead to a hypothesis regarding the social reception of people with intellectual 382 impairments and their families (Beighton \& Wills, 2017; Mitter et al., 2019). This issue could be 383 considered in line with reports of higher social exclusion among people with severe autism 384 spectrum disorder symptoms when compared to those with less strong symptoms (Mitter et al., 385 2019). Once more, it can be hypothesized that it is not the severity of the child's symptoms that is 386 critical in the case of the parents' experience of care; however, due to the insufficient amount of 387 data in this area in the current study, these assumptions are of purely speculative nature and 388 require further research.

\section{Conclusions}

The current study showed that self-compassion may act as a significant moderator between affiliate stigma, fusion and depression or stress. Parents of children with autism spectrum disorder characterized by higher intensity of self-compassion were less likely to experience negative symptoms due to self-stigmatizing thoughts when compared to those with low self-compassion. Additionally, the results obtained suggest that cognitive fusion is moderately related to self-stigma (both affiliate and public) which may suggest that a rigid and narrow perspective about oneself is a psychological mechanism that underlies self-stigma. Hence, interventions focused on the development of defusion and self-compassion, not self-stigma per se, might be considered as imperative in reducing negative effects of self-stigma and distress.

Despite its strengths such as an adequate sample size $(\mathrm{N}=233)$, the present study has certain limitations. It must be highlighted that the majority of the study participants were female, hence the results obtained must be considered more as an experience of mothers than of fathers.

403 Future research should focus on developing knowledge regarding the experiences of fathers of children with ASD, as it can be hypothesized that it varies from the ones reported by the mothers, as research shows significant gender differences e.g. in terms of self-compassion (Yarnell et al., 2019).

Of primary concern, the study design was cross-sectional hence it must be highlighted that longitudinal studies concerned with the development of self-compassion and fusion as well as its 
411 of acceptance and commitment therapy (or training) in parents of children with ASD focused on 412 self-stigmatizing thoughts and social contexts of care in order to develop self-compassion and 413 defusion. Previous research shows that micro-, two-session interventions (Blackledge \& Hayes, 414 2006; Hahs et al., 2019) or short ACT training sessions (Poddar et al., 2015) are effective in 415 terms of enhancing quality of life and decreasing negative symptoms in this group, as well as in 416 reducing self-stigma in other minorities (Yadavaia \& Hayes, 2012; Luoma et al., 2008). Perhaps 417 development of other aspects of psychological flexibility - e.g. self-as-context - would be of use. 418

\section{Acknowledgements}

420 We would like to thank Ada Stasiak, Karolina Kawa, Oliwia Kuczka and Weronika 421 Szubert from the University of Silesia in Katowice for their assistance in obtaining data. 
422

423

424

425

426

427

428

429

430

431

432

433

434

435

436

437

438

439

440

441

442

443

444

445

446

447

448

449

450

\section{References}

Baran, L., Hyla, M., \& Kleszcz, B. (2019). ELASTYCZNOŚĆ PSYCHOLOGICZNA. Polska adaptacja narzędzi pomiarowych dla praktyków i badaczy. Wydawnictwo Uniwersytetu Śląskiego.

Basharpoor, S., Mowlaie, M., Sarafrazi, L. (2020). The Relationship of Distress Tolerance, SelfCompassion to Posttraumatic Growth, the Mediating Role of Cognitive Fusion. Journal of Maltreatment, Aggression \& Trauma. https://doi.org/10.1080/10926771.2019.1711279

Beighton, C., \& Wills, J. (2017). Are parents identifying positive aspects to parenting their child with an intellectual disability or are they just coping? A qualitative exploration. Journal of Intellectual Disability, 21, 325-345. DOI: 10.1177/1744629516656073

Broady, T. R., Stoyles, G. J., \& Morse, C. (2017). Understanding carers’ lived experience of stigma: the voice of families with a child on the autism spectrum. Health \& social care in the community, 25(1), 224-233. DOI: 10.1111/hac.12297

Butler, R. C., \& Gillis, J. M. (2011). The impact of labels and behaviors on the stigmatization of adults with Asperger's disorder. Journal of autism and developmental disorders, 41(6), 741-749. DOI: 10.1007/s10803-010-1093-9

Carvalho, S. A., Pinto-Gouveia, J., Gillanders, D., Castilho, P. (2018). Pain and Depressive Symptoms: Exploring Cognitive Fusion and Self-Compassion in a Moderated Mediation Model. The Journal of Psychology. doi: 10.1080/00223980.2018.1507990

Chan, K. K. S., \& Lam, C. B. (2017). Trait mindfulness attenuates the adverse psychological impact of stigma on parents of children with autism spectrum disorder. Mindfulness, 8(4), 984-994. https://doi.org/10.1007/s12671-016-0675-9

Chan, K. K. S., \& Lam, C. B. (2018). Self-stigma among parents of children with autism spectrum disorder. Research in Autism Spectrum Disorders, 48, 44-52. https://doi.org/10.1016/j.rasd.2018.01.001

Chin, F., \& Hayes, S. C. (2017). Acceptance and Commitment Therapy and the Cognitive Behavioral Tradition: Assumptions, Model, Methods, and Outcomes. In: The Science of Cognitive Behavioral Therapy Eds.: Hoffman, S. G., \& Asmundson, G. J. G. Academic Press. 
451 Corrigan, P. W., Watson, A. C. (2002). The paradox of self-stigma and mental illness. Clinical Psychology: Science and Practice, 9, 35-53. https://doi.org/10.1093/clipsy.9.1.35

453 Corrigan, P. W., Rafacz, J., \& Rüsch, N. (2011). Examining a progressive model of self-stigma and its impact on people with serious mental illness. Psychiatry research, 189(3), 339343. doi: 10.1016/j.psychres.2011.05.024

456

Dickerson, S.S., Gruenewald, T.L., Kemeny, M.E. (2004) When the social self is threatened: Shame, physiology, and health. Journal of Personality, 72: 1192-1216. DOI: 10.1111/j.1467-6494.2004.00295.x

Dorahy, M. (2010). The impact of dissociation, shame, and guilt on interpersonal relationships in chronically traumatized individuals: A pilot study. Journal of Traumatic Stress, 23: 653656. DOI: $10.1002 /$ jts.20564

Forman, E. M., Herbert, J. D., Moitra, E., Yeomans, P. D., \& Geller, P. A. (2007). A randomized controlled effectiveness trial of acceptance and commitment therapy and cognitive therapy for anxiety and depression. Behavior modification, 31(6), 772-799. DOI: 10.1177/0145445507302202

Gillanders, D. T., Sinclair, A. K., MacLean, M., Jardine, K. (2015). Illness cognitions, cognitive fusion, avoidance and self-compassion as predictors of distress and quality of life in a heterogeneous sample of adults, after cancer. Journal of Contextual Behavioral Science, 4(4), 300-311. doi: 10.1016/j.jcbs.2015.07.003

Gillanders, D.T., Bolderston, H., Bond, F.W., Dempster, M., Flaxman, P. E., Campbell, L., Masley, S., et al. (2014). The development and initial validation of the Cognitive Fusion Questionnaire. Behavior Therapy, 45(1), 83-101. DOI: 10.1016/j.beth.2013.09.001

Goetz, J.L., Keltner, D., Simon-Thomas, E. (2010) Compassion: an evolutionary analysis and empirical review. Psychological Bulletin, 136: 351-374. https://doi.org/10.1037/a0018807

Hahs, A. D., Dixon. M. R., \& Paliliunas, D. (2019). Randomized controlled trial of a brief acceptance and commitment training for parents of individuals diagnosed with autism spectrum disorders. Journal of Contextual Behavioral Science, 12, 154-159. https://doi.org/10.1016/j.jcbs.2018.03.002 
479 Hamlyn-Wright, S., Draghi-Lorenz, R., \& Ellis, J. (2007). Locus of control fails to mediate

480

481

482

483

484

485

486

487

488

489

490

491

492

493

494

495

496

497

498

499

500

501

502

503

504

505

506

507

between stress and anxiety and depression in parents of children with a developmental disorder. Autism, 11(6), 489-501. DOI: 10.1177/1362361307083258

Harris, R. (2012). Reality Slap: Finding Peace and Fulfillment When Life Hurts. New Harbinger Publications.

Hayes, S. A., \& Watson, S. L. (2013). The impact of parenting stress: A meta-analysis of studies comparing the experience of parenting stress in parents of children with and without autism spectrum disorder. Journal of autism and developmental disorders, 43(3), 629642. DOI: 10.1007/s10803-012-1604-y

Hayes, S. C. (2004). Acceptance and commitment therapy and the new behavior therapies: Mindfulness, acceptance, and relationship. In S.C. Hayes, V.M. Follette \& M.M. Linehan (Eds.), Mindfulness and acceptance: Expanding the cognitive behavioral tradition (pp. 129). New York, NY: Guilford.

Hayes, S. C., \& Hofmann, S. G. (2017). The third wave of cognitive behavioral therapy and the rise of process based care. World Psychiatry, 16(3), 245. doi: 10.1002/wps.20442

Hayes, S., Strosahl, K.D., \& Wilson, K. (1999). Acceptance and Commitment Therapy: An Experiential Approach to Behavior Change. Guilford Press, New York.

Hilbert, A., Braehler, E., Schmidt, R., Lowe, B., Hauser, W., Zenger, M. (2015). Self-compassion as a resource in the self-stigma process of overweight and obese individuals. Obesity Facts, 8(5), 293-301. https://doi.org/10.1159/000438681.

Hofmann, S. G., \& Hayes, S. C. (2019). The Future of Intervention Science: Process-Based Therapy. Clinical Psychological Science, 7(1), 37-50.

Kahl, K. G., Winter, L., \& Schweiger, U. (2012). The third wave of cognitive behavioral therapies: what is new and what is effective?. Current opinion in psychiatry, 25(6), 522528. DOI: 10.1097/YCO.0b013e328358e531

Kinnear, S. H., Link, B. G., Ballan, M. S., \& Fischbach, R. L. (2016). Understanding the experience of stigma for parents of children with autism spectrum disorder and the role stigma plays in families’ lives. Journal of Autism and Developmental Disorders, 46(3), 942-953. DOI: 10.1007/s10803-015-2637-9

Peer) reviewing PDF | (2021:05:61799:1:1:NEW 5 Nov 2021) 
508 Kirby, J.N., Tellegen, C.L. Steindl, S.R. (2017). A Meta-Analysis of Compassion-Based 509 Interventions: Current State of Knowledge and Future Directions, Behavior Therapy. doi: $510 \quad$ 10.1016/j.beth.2017.06.003

511 Lillis, J., Hayes, S.C., Bunting, K., Masuda, A. (2009) Teaching acceptance and mindfulness to 512 improve the lives of the obese: a preliminary test of a theoretical model. Annals of 513 Behavioral Medicine, 37: 58-69. DOI: 10.1007/s12160-009-9083-X

514 Lovell, B., \& Wetherell, M. A. (2019). Affiliate stigma, perceived social support and perceived 515 stress in caregivers of children with autism spectrum disorder: A multiple mediation study. Archives of psychiatric nursing, 33(5), 31-35. DOI: 10.1016/j.apnu.2019.08.012

Lovibond, S.H. \& Lovibond, P.F. (1995). Manual for the Depression Anxiety \& Stress Scales. (2nd Ed.)Sydney: Psychology Foundation.

Luoma, J. B., \& Platt, M. G. (2015). Shame, self-criticism, self-stigma, and compassion in acceptance and commitment therapy. Current Opinion in Psychology, 2, 97-101. doi.org/ 10.1016/j.copsyc.2014.12.016

Luoma, J.B., Kohlenberg, B.S., Hayes, S.C., Fletcher, L. (2012). Slow and steady wins the race: A randomized clinical trial of acceptance and commitment therapy targeting shame in substance use disorders. Journal of consulting and clinical psychology, 80: 43-53. DOI: $10.1037 / \mathrm{a} 0026070$

Luoma, J. B., Kohlenberg, B. S., Hayes, S. C., Bunting, K., \& Rye, A. K. (2008). Reducing selfstigma in substance abuse through acceptance and commitment therapy: Model, manual development, and pilot outcomes. Addiction research \& theory, 16(2), 149-165. https://doi.org/10.1080/16066350701850295

Maisel, M. E., Stephenson, K. G., Cox, J. C., \& South, M. (2019). Cognitive defusion for reducing distressing thoughts in adults with autism. Research in Autism Spectrum Disorders, 59, 33-45. DOI:10.1016/J.RASD.2018.12.005

Mak, W. W. S., \& Cheung, R. Y. M. (2010). Self-stigma among concealable minorities in Hong Kong: Conceptualization and unified measurement. American Journal of Orthopsychiatry, 80(2), 267-281. https://doi.org/10.1111/j.1939-0025.2010.01030.x 
536 Makara-Studzińska, M., Petkowicz, B., Urbańska, A., Petkowicz, J.. (In preparation). „Polska

537

538

539

540

541

542

543

544

545

546

547

548

549

550

551

552

553

554

555

556

557

558

559

560

561

562

563

564 wersja kwestionariusza DASS-21.” Retrieved May 8, 2021, from http://www2.psy.unsw.edu.au/dass/Polish/Polish.htm.

Martin, M. M., Staggers, S. M., Anderson, C. M. (2011). The Relationships Between Cognitive Flexibility with Dogmatism, Intellectual Flexibility, Preference for Consistency, and SelfCompassion. Communication Research Reports, 28:3, 275-280. doi: 10.1080/08824096.2011.587555

Marsh, I.C., Chan, S.W.Y. \& MacBeth, A. (2018). Self-compassion and Psychological Distress in Adolescents-a $\quad$ Meta-analysis. Mindfulness, $\quad 9, \quad$ 1011-1027. https://doi.org/10.1007/s12671-017-0850-7

Masuda, A., Hayes, S. C., Fletcher, L. B., Seignourel, P. J., Bunting, K., Herbst, S. A., Twohig, M. P., Lillis, J. (2007). Impact of acceptance and commitment therapy vs education on stigma toward people with psychological disorders. Behaviour Research and Therapy, 45, 2764-2772. DOI: 10.1016/j.brat.2007.05.008

Mitter, N., Ali, A., \& Scior, K. (2019). Stigma experienced by families of individuals with intellectual disabilities and autism: A systematic review. Research in Developmental Disabilities, 89, 10-21. DOI: 10.1016/j.ridd.2019.03.001

Mowlaie, M., Mikaeili, N., Agababaei, N., Ghaffari, M., \& Pouresmali, A. (2017). The relationships of sense of coherence and self-compassion to worry: The Mediating role of personal intelligence. Current Psychology, 36(3), 630-636. doi:10.1007/s12144-0169451-1

Myers, B. J., Mackintosh, V. H., Goin-Kochel, R. P. (2009). “My Greatest Joy and my Greatest Heartache”: Parents’ Own Words on How Having a Child in the Autism Spectrum Has Affected their Lives and their Families’ Lives. Research in Autism Spectrum Disorders, 3, 670-684. DOI: 10.1016/j.rasd.2009.01.004

Neff. K. (2003a). The development and validation of a scale to measure self-compassion. Self and Identity, 2, 223-250. doi:10.1080/15298860390209035.

Neff, K. D. (2003b). Self-compassion: an alternative conceptualization of a healthy attitude toward oneself. Self and Identity, 2, 85-101. https://doi.org/10.1080/15298860309032 
565 Neff, K. D., \& McGeheea, P. (2010). Self-compassion and psychological resilience among adolescents and young adults. Self and Identity, 9, 225-240. doi:10.1080/15298860902979307

Neff, K. D., Rude, S. S., Kirkpatrick, K. L. (2007). An examination of self-compassion in relation to positive psychological functioning and personality traits. Journal of Research in Personality, 41(4), 908-916. doi:10.1016/j.jrp.2006.08.002

Neff, K., Tirch, D. (2013) Self-compassion and ACT. In Mindfulness, Acceptance, and Positive Psychology: The Seven Foundations of Well-being. Edited by Kashdan, T.B., Ciarrochi, J. Context Press/New Harbinger: 78-106.

Quinn, D.M., Williams, M. K., Weisz, B. M. (2015). From discrimination to internalized mental illness stigma: the mediating roles of anticipated discrimination and anticipated stigma. Psychiatric Rehabilitation, 38(2), 103-108. https://doi.org/10.1037/prj0000136

Raes, F., Pommier, E., Neff, K. D., \& Van Gucht, D. (2011). Construction and factorial validation of a short form of the Self-Compassion Scale. Clinical Psychology \& Psychotherapy, 18(3), 250-255. https://doi.org/10.1002/cpp.702

Skinta, M.D., Lezama, M., Wells, G., Dilley, J.W. (2014). Acceptance and Compassion-Based Group Therapy to Reduce HIV Stigma. Cognitive and Behavioral Practice 22(4), 481490. https://doi.org/10.1016/j.cbpra.2014.05.006

Smith-Palmer, J., Cerri, K., Sbarigia, U., Chan, E. K. H., Pollock, R. F., Valentine, W. J., Bonroy, K. (2020). Impact of Stigma on People Living with Chronic Hepatitis B. Patient Related Outcome Measures, 11, 95-107. DOI https://doi.org/10.2147/PROM.S226936 Stigma as a Barrier to Recovery: The Extent to Which Caregivers Believe Most People Devalue Consumers and Their Families. Psychiatric Services, 52(12), 1633-1638. https:// doi.org/10.1176/appi.ps.52.12.1633 
594 Trompetter, H. R., de Kleine, E., Bohlmeijer, E. T. (2017). Why does positive mental health buffer against psychopathology? An exploratory study on self-compassion as a resilience mechanism and adaptive emotion regulation strategy. Cognitive Therapy and Research, 41(3), 459-468. https://doi.org/10.1007/s10608-016-774-0.

Valvano, A., Floyd, R. M., Penwell-Waines, L., Stepleman, L., Lewis, K., House, A. (2016). The relationship between cognitive fusion, stigma, and well-being in people with multiple sclerosis. Journal for Contextual Behavioral Science, 5, 266-270. https://doi.org/10.1016/ j.jcbs.2016.07.003

Vowles, K. E., Witkiewitz, K., Sowden, G., Ashworth, J. (2014). Acceptance and commitment therapy for chronic pain: Evidence of mediation and clinically significant change following an abbreviated interdisciplinary program of rehabilitation. The Journal of Pain,

Wong, C. C. Y., Knee, R. C., Neighbors, C., Zvolensky, M. J. (2018). Hacking Stigma by Loving Yourself: A Mediated-Moderation Model of Self-Compassion and Stigma. Mindfulness 10, 415-433. https://doi.org/10.1007/s12671-018-0984-2

Wong, C. C. Y., Mak, W. W. S., Liao, K. Y. H. (2016). Self-compassion: A potential buffer against affiliate stigma experienced by parents of children with autism spectrum disorders. Mindfulness, 7(6), 1385-1395. https://doi.org/10.1007/s12671-016-0580-2

Yadavaia, J.E., \& Hayes, S.C. (2012) Acceptance and commitment therapy for self-stigma around sexual orientation: A multiple baseline evaluation. Cognitive and Behavioral Practice, 19: 545-559. https://doi.org/10.1016/j.cbpra.2011.09.002 1136-1152. https://doi.org/10.1007/s12671-018-1066-1 
Table $\mathbf{1}$ (on next page)

Sociodemographic data 
1 Table 1. Sociodemographic data.

$\mathrm{N}=233 \quad \%$

\section{Age of parent}

Range

Mean

Standard deviation

Gender of parent

Male

Female

Level of education

Primary education

Secondary education

Higher education

Professional status

Full-time job

100

108

25

Unemployed

Marital status

Single

Married

7

166

29

29

Divorced

Widow/-er

Age of child

Range

2-37

Mean

Standard deviation

10.15

5.44

\section{Gender of child}

Male

196

84.12

Female

37

Level of child's intellectual

disability

No intellectual disability

52.36

Mild
6.44

93.56

3.00

39.91

57.08

42.92

46.35

10.73

3.00

71.24

12.45

12.45

.86
Moderate

36

22.75

15.45 
Table 2 (on next page)

Descriptive statistics and Pearson's $r$ correlations 
1 Table 2. Descriptive statistics and Pearson's r correlations.

\begin{tabular}{|l|c|c|c|c|c|c|c|c|c|}
\hline & $\mathrm{M}$ & $\mathrm{SD}$ & $\mathbf{1 .}$ & $\mathbf{2 .}$ & $\mathbf{3 .}$ & $\mathbf{4 .}$ & $\mathbf{5 .}$ & $\mathbf{6 .}$ & $\mathbf{7 .}$ \\
\hline $\begin{array}{l}\text { 1. Affiliate } \\
\text { stigma }\end{array}$ & 18.50 & 8.49 & - & & & & & & \\
\hline $\begin{array}{l}\text { 2. Public } \\
\text { stigma }\end{array}$ & 23.77 & 6.68 & $.47^{* * *}$ & - & & & & & \\
\hline $\begin{array}{l}\text { 3. Self- } \\
\text { compassion }\end{array}$ & 33.28 & 9.06 & $-.24^{* * *}$ & $-.32^{* * *}$ & - & & & & \\
\hline $\begin{array}{l}\text { 4. Cognitive } \\
\text { fusion }\end{array}$ & 31.37 & 11.11 & $.31^{* * *}$ & $.33^{* * *}$ & $-.64^{* * *}$ & - & & & \\
\hline 5. Depression & 16.65 & 10.55 & $.33^{* * *}$ & $.36^{* * *}$ & $-.54^{* * *}$ & $.66^{* * *}$ & & & \\
\hline 6. Anxiety & 18.96 & 11.14 & $.35^{* * *}$ & $.38^{* * *}$ & $-.59^{* * *}$ & $.64^{* * *}$ & $.92^{* * *}$ & & \\
\hline 7. Stress & 14.02 & 10.86 & $.35^{* * *}$ & $.37^{* * *}$ & $-.52^{* * *}$ & $.65^{* * *}$ & $.95^{* * *}$ & $.94^{* * *}$ & - \\
\hline
\end{tabular}

$2 * \mathrm{p}<.05, * * \mathrm{p}<.01, * * * \mathrm{p}<.001$

3 
Table 3 (on next page)

Hierarchical regression model, affiliate stigma 
1 Table 3. Hierarchical regression model, affiliate stigma

\begin{tabular}{|c|c|c|c|c|c|c|c|c|c|}
\hline & \multicolumn{3}{|c|}{ Depression } & \multicolumn{3}{|c|}{ Anxiety } & \multicolumn{3}{|c|}{ Stress } \\
\hline & Step 1 & Step 2 & Step 3 & Step 1 & Step 2 & Step 3 & Step 1 & Step 2 & Step 3 \\
\hline Background factors, $\beta$ & & & & & & & & & \\
\hline Professional status & -.05 & -.02 & -.03 & -.06 & -.03 & -.03 & -.06 & -.02 & -.03 \\
\hline Parental education level & $.20 * *$ & $.20 * * *$ & $.20 * * *$ & $.19 *$ & $.19 * * *$ & $.19 * * *$ & $.16^{*}$ & $.16^{* *}$ & $.16 * * *$ \\
\hline $\begin{array}{l}\text { Level of child's } \\
\text { intellectual disability }\end{array}$ & .04 & .02 & .03 & .10 & .08 & .09 & .10 & .08 & .09 \\
\hline Main effects, $\beta$ & & & & & & & & & \\
\hline Affiliate stigma & & $.16^{* *}$ & $.16 * * *$ & & $.18 * * *$ & $.19 * * *$ & & $.18 * * *$ & $.19 * * *$ \\
\hline Self-compassion & & $-.17 * *$ & $-.18 * *$ & & $-.27 * * *$ & $-.28 * * *$ & & $-.14 *$ & $-.15 * *$ \\
\hline Cognitive fusion & & $.50 * * *$ & $.53 * * *$ & & $.41 * * *$ & $.43 * * *$ & & $.50 * * *$ & $.53 * * *$ \\
\hline Interaction effects, $\beta$ & & & & & & & & & \\
\hline $\begin{array}{l}\text { Affiliate stigma } \mathrm{x} \text { self- } \\
\text { compassion }\end{array}$ & & & -.04 & & & -.06 & & & $-.10 *$ \\
\hline $\begin{array}{l}\text { Cognitive fusion x self- } \\
\text { compassion }\end{array}$ & & & $-.10 *$ & & & -.04 & & & -.07 \\
\hline$\Delta \mathrm{R}$ & .02 & .48 & .01 & .04 & .47 & .00 & .01 & .46 & .02 \\
\hline
\end{tabular}

2

$* \mathrm{p}<.05, * * \mathrm{p}<.01, * * * \mathrm{p}<.001$ 
Table 4 (on next page)

Hierarchical regression model, public stigma 
1 Table 4. Hierarchical regression model, public stigma

\begin{tabular}{|c|c|c|c|c|c|c|c|c|c|}
\hline & \multicolumn{3}{|c|}{ Depression } & \multicolumn{3}{|c|}{ Anxiety } & \multicolumn{3}{|c|}{ Stress } \\
\hline & Step 1 & Step 2 & Step 3 & Step 1 & Step 2 & Step 3 & Step 1 & Step 2 & Step 3 \\
\hline Background factors, $\beta$ & & & & & & & & & \\
\hline Professional status & -.05 & -.04 & -.05 & -.06 & -.05 & -.05 & -.06 & -.04 & -.05 \\
\hline Parental education level & $.20 * *$ & $.17 * * *$ & $.18 * * *$ & $.19^{*}$ & $.16^{* * *}$ & $.16^{* * *}$ & $.16^{*}$ & $.13 * *$ & $.13 * *$ \\
\hline $\begin{array}{l}\text { Level of child's } \\
\text { intellectual disability }\end{array}$ & .04 & .02 & .01 & .10 & .07 & .07 & .10 & .07 & .07 \\
\hline Main effects, $\beta$ & & & & & & & & & \\
\hline Public stigma & & $.13 * *$ & $.14 * *$ & & $.15^{* *}$ & $.16^{* *}$ & & $.15^{* *}$ & $.16^{* * *}$ \\
\hline Self-compassion & & $-.16 * *$ & $-.17 * *$ & & $.26 * * *$ & $.27 * * *$ & & $-.13 *$ & $-.14 *$ \\
\hline Cognitive fusion & & $.54 * * *$ & $.54 * * *$ & & $.43 * * *$ & $.44 * * *$ & & $.51 * * *$ & $.54 * * *$ \\
\hline Interaction effects, $\beta$ & & & & & & & & & \\
\hline $\begin{array}{l}\text { Public stigma } \mathrm{x} \text { self- } \\
\text { compassion }\end{array}$ & & & -.03 & & & -.04 & & & -.04 \\
\hline $\begin{array}{l}\text { Cognitive fusion x self- } \\
\text { compassion }\end{array}$ & & & $-.11 *$ & & & -.05 & & & $-.11 *$ \\
\hline$\Delta \mathrm{R}$ & .02 & .47 & .01 & .04 & .47 & .00 & .01 & .45 & .02 \\
\hline
\end{tabular}

$* \mathrm{p}<.05, * * \mathrm{p}<.01, * * * \mathrm{p}<.001$ 


\section{Figure 1}

Figure 1. Simple slope test, moderating effect of self-compassion between fusion and depression.

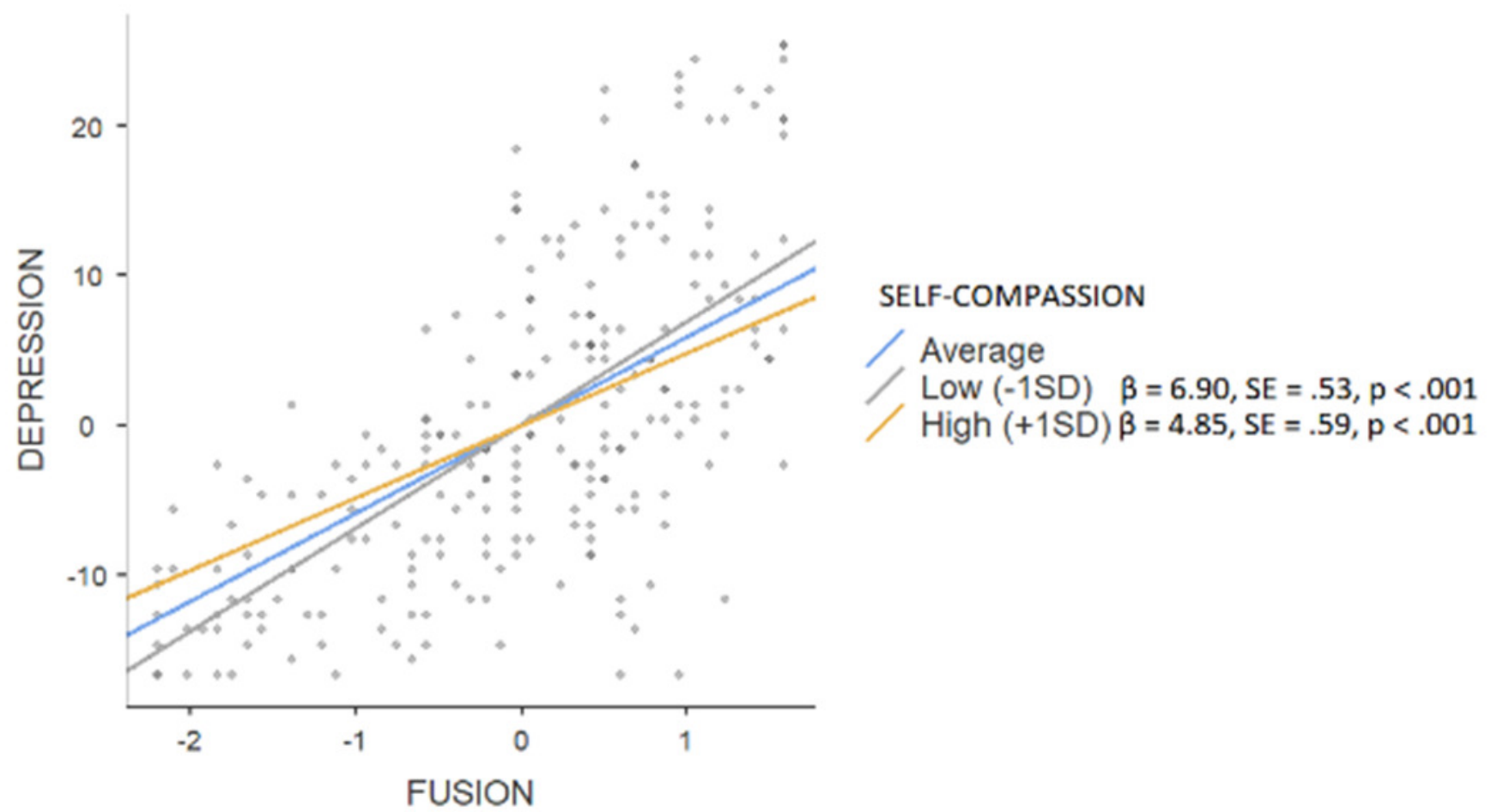


Figure 2

Figure 2. Simple slope test, moderating effect of self-compassion between affiliate stigma and stress

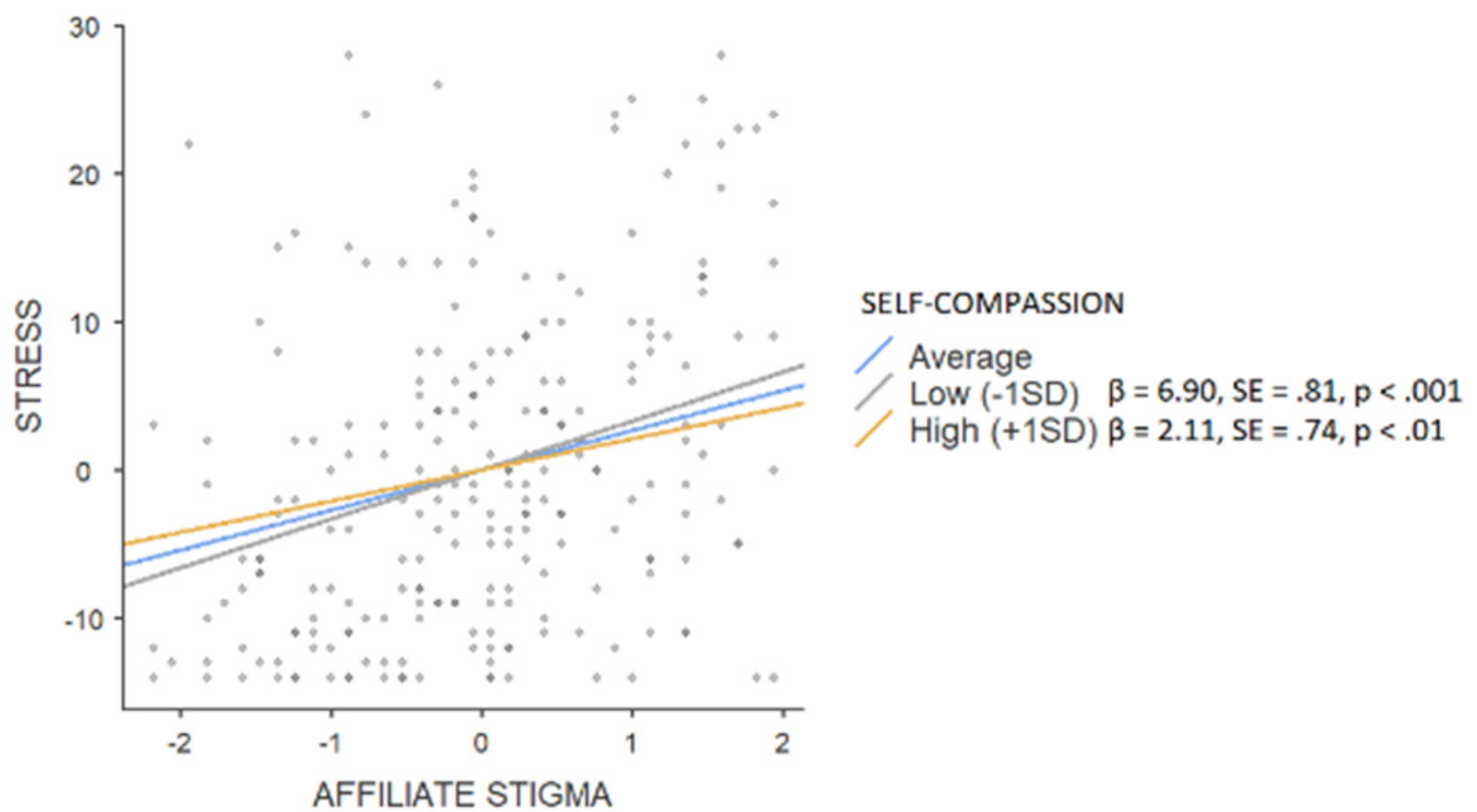


Figure 3

Figure 3. Simple slope test, moderating effect of self-compassion between fusion and depression

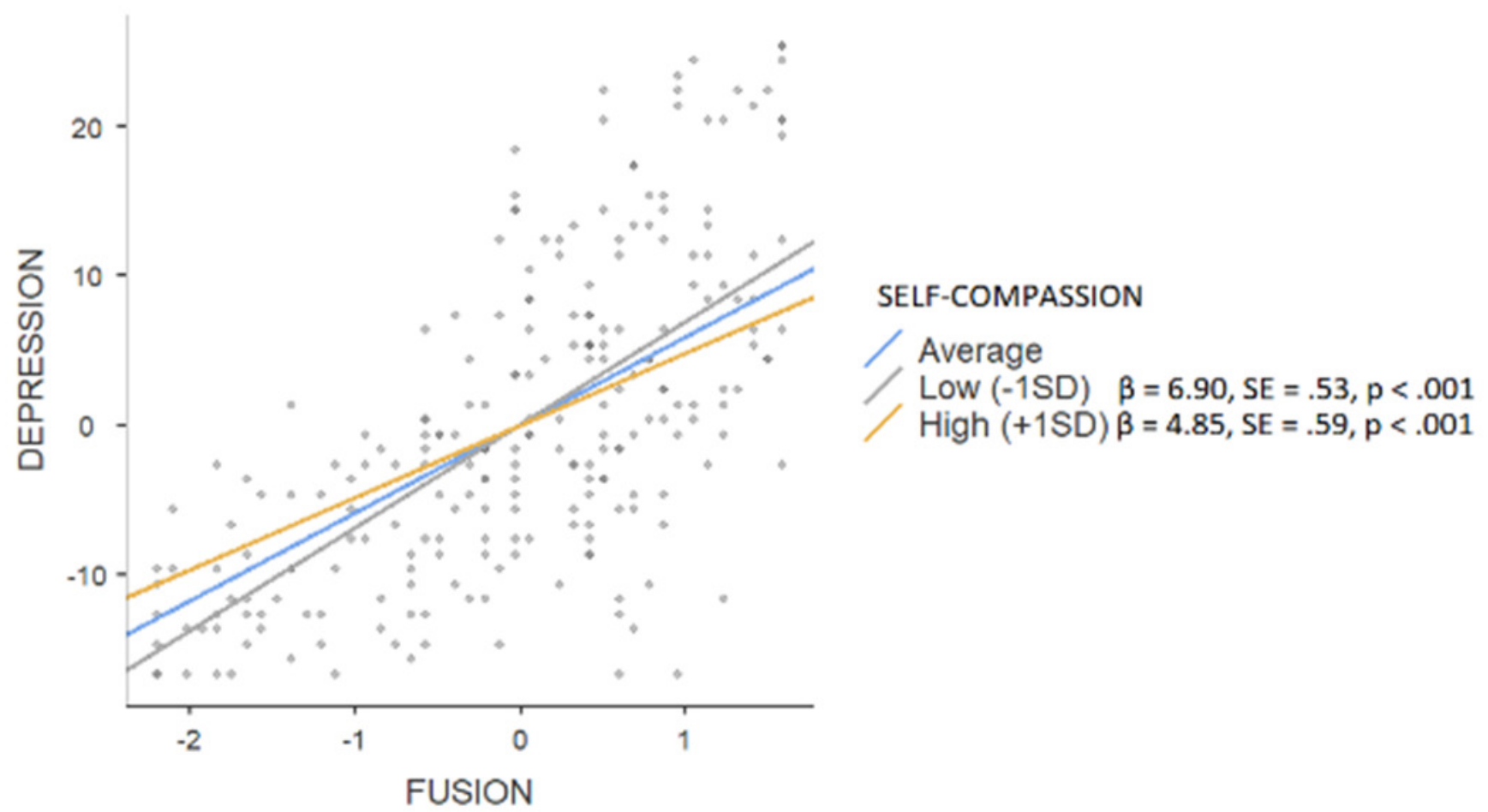


Figure 4

Figure 4. Simple slope test, moderating effect of self-compassion between fusion and stress

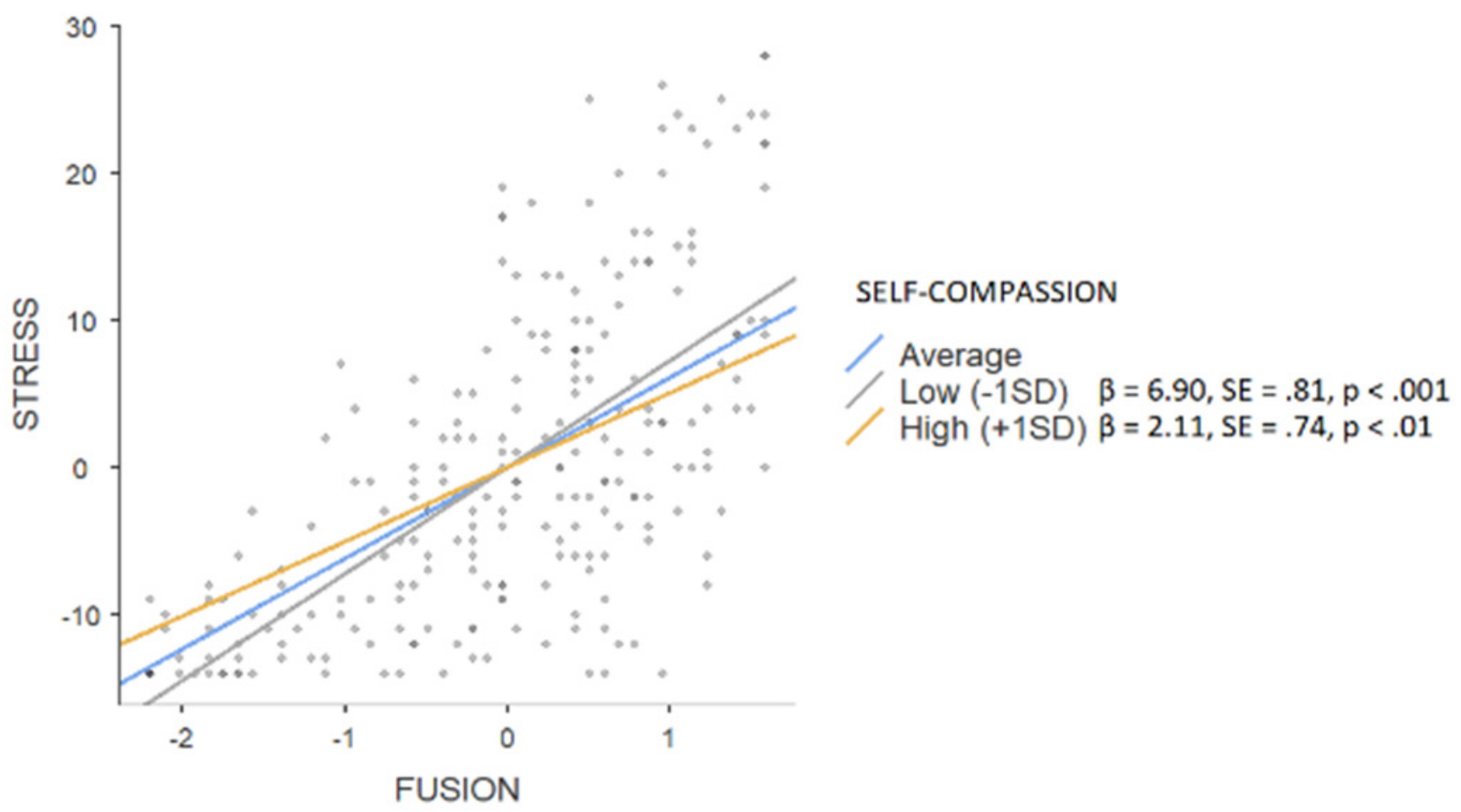

